\title{
Autopsy Findings in 32 Patients with COVID-19: A Single-Institution Experience
}

\author{
Sarah S. Elsoukkary ${ }^{a} \quad$ Maria Mostyka ${ }^{a} \quad$ Alicia Dillard ${ }^{a}$ Diana R. Berman ${ }^{a}$ \\ Lucy X. Ma ${ }^{a}$ Amy Chadburn $^{\mathrm{b}}$ Rhonda K. Yantiss $^{\mathrm{b}}$ Jose Jessurun ${ }^{\mathrm{b}}$ \\ Surya V. Seshan ${ }^{b}$ Alain C. Borczuk ${ }^{b}$ Steven P. Salvatore ${ }^{b}$ \\ ${ }^{a}$ Department of Pathology and Laboratory Medicine, NewYork-Presbyterian Hospital, New York, NY, USA; \\ bWeill Cornell Medicine, New York, NY, USA
}

\section{Keywords}

COVID-19 · Autopsy · Thrombi · Acute respiratory distress syndrome

\begin{abstract}
Background: A novel coronavirus, SARS-CoV-2, was identified in Wuhan, China in late 2019. This virus rapidly spread around the world causing disease ranging from minimal symptoms to severe pneumonia, which was termed coronavirus disease (i.e., COVID). Postmortem examination is a valuable tool for studying the pathobiology of this new infection. Methods: We report the clinicopathologic findings from 32 autopsy studies conducted on patients who died of COVID-19 including routine gross and microscopic examination with applicable special and immunohistochemical staining techniques. Results: SARS-CoV-2 infection was confirmed by nasopharyngeal RT-PCR in 31 cases (97\%) and by immunohistochemical staining for SARS-CoV-2 spikeprotein in the lung in the remaining 1 case (3\%). The ethnically diverse cohort consisted of 22 males and 10 females with a mean age of 68 years (range: $30-100)$. Patients most commonly presented with cough (17 [55\%]), shortness of breath (26 [81\%]), and a low-grade fever (17 [55\%]).
\end{abstract}

Thirty-one (97\%) of the patients had at least 1 comorbidity (mean $=4)$. Twenty-eight patients $(88 \%)$ had widespread thromboembolic disease, as well as diffuse alveolar damage (30 [94\%]), diabetic nephropathy (17 [57\%]) and acute tubular injury. Patterns of liver injury were heterogeneous, featuring 10 (36\%) with frequent large basophilic structures in sinusoidal endothelium, and increased immunoblast-like cells in lymph nodes. Conclusion: This series of autopsies from patients with COVID-19 confirms the observation that the majority of severely affected patients have significant pulmonary pathology. However, many patients also have widespread microscopic thromboses, as well as characteristic findings in the liver and lymph nodes.

(c) 2020 The Author(s)
Published by S. Karger AG, Basel

\section{Introduction}

Coronaviruses (CoVs) are single-stranded, enveloped RNA viruses that cause respiratory illnesses among humans and animals $[1,2]$. These ubiquitous viruses cause variably severe diseases that range from the common cold to severe acute respiratory syndrome (SARS) and Middle East respiratory syndrome (MERS). Several cases of karger@karger.com www.karger.com/pat

Karger $\stackrel{\text { ' }}{5}$

GOPEN ACCESS
(C) 2020 The Author(s)

Published by S. Karger AG, Basel

This is an Open Access article licensed under the Creative Commons Attribution-NonCommercial-4.0 International License (CC BY-NC) (http://www.karger.com/Services/OpenAccessLicense), applicable to the online version of the article only. Usage and distribution for commercial purposes requires written permission.
Steven P. Salvatore

Pathology and Laboratory Medicine

Weill Cornell Medicine/NewYork-Presbyterian Hospital

1300 York Ave, Box 69, New York, NY 10065 (USA) sts9057@ med.cornell.edu 
pneumonia reported in Wuhan, China in late 2019 led to identification of a novel coronavirus, later designated as SARS coronavirus-2 (SARS-CoV-2), the etiologic agent of COVID-19 [3, 4]. Since that time, SARS-CoV-2 has spread rapidly across the world causing more than ten million infections and more than half a million deaths by early summer 2020 [5].

Coronaviruses gain entry into cells via the angiotensin-converting enzyme 2 (ACE2), which is expressed in multiple tissue types [6]. The virus disproportionately affects the respiratory system and, unlike SARS and MERS, disproportionately affects older patients with comorbidities such as hypertension, diabetes, obesity, and cardiovascular disease [4]. The reasons for this pattern of morbidity and mortality are yet to be elucidated. Extrapulmonary manifestations of the disease have not yet been fully described.

Postmortem examination is an invaluable tool in understanding the pathobiology of disease. This study contributes to the growing data on this topic [7-18]. The purpose of this study is to describe clinical and pathologic findings in major organ systems of patients who died from SARS-CoV-2 infection.

\section{Methods}

\section{Autopsy Examination}

Written or verbal informed consent was obtained for postmortem examination from the next of kin of 32 patients with confirmed or presumed COVID-19. Cases were confirmed by SARS-CoV-2 RT-PCR testing in 31 (97\%) patients and by tissuebased immunohistochemical staining for SARS-CoV-2 spike protein in 1 case $(3 \%)$ of a patient who died at home and had not been tested previously, but had symptoms and positive family contacts. Clinical information and laboratory data were obtained from the patients' electronic medical records. Postmortem examination of the brain was not performed due to potential infectious risk related to extraction. Two (6\%) examinations were limited to the chest, one (3\%) was confined to the right lung only, and one (3\%) was limited to lung biopsies. The remaining $28(88 \%)$ cases included examination of all thoracic and abdominal organs. The autopsies were performed from 5 to $382 \mathrm{~h}$ (median: 43) following death. Photographs were taken, and representative sections submitted of all the organs and grossly visible lesions.

Immunohistochemical Evaluation and Ancillary Studies

The lungs were insufflated with formalin prior to sectioning. Tissue specimens were fixed in $10 \%$ formalin for at least $24 \mathrm{~h}$ prior to processing. Microscopic examination of all tissue sections was performed on hematoxylin and eosin-stained slides. Immunohistochemical stains were performed on select cases and included CD61 (clone 2F2, Leica NCL-CD61-308), CD163 (clone 10D6, Leica NCL-CD163), ERG (clone EPR3864, Ventana 6478450001),
CD3 (clone SP7, Fisher RM-9107-S), CD20 (clone L26, Leica NCLCD20-L26), and C5b-9 (clone AE11, Quidel A239). Special stains performed on various tissue types included PAS, PAS with diastase, iron, trichrome, reticulin, GMS, AFB, Brown Hopps Gram (BHG), and Warthin-Starry. Microscopic examination and interpretation of ancillary stains were performed by 5 pathologists (S.P.S., A.C.B., S.V.S., J.J., A.C.).

The study was deemed exempt by the institutional review board.

Statistical Analysis

Data normally distributed were presented as means and ranges. Categorical variables were summarized as counts and percentages. Statistical analysis was performed with Microsoft Excel.

\section{Results}

\section{Clinical Information}

Patient demographics and clinical information are summarized in Table 1 and laboratory findings in Table 2. The ratio of males to females was $2.2: 1$, with an average age of 68 years old (range $=30-100$ years). Thirty-seven percent of the patients were White, $31 \%$ were Hispanic, $16 \%$ were Asian, and $16 \%$ were Black. Most (72\%) were admitted to the hospital from home or died at home. Twenty-two percent were from a nursing home, and 6\% were homeless. Fifty-three percent of the patients had no history of smoking, $25 \%$ were former smokers (mean pack-year $=40$, range $=10-120)$, and for $7(22 \%)$ it was unknown. None of the patients were known to be current smokers. No correlation was seen for patients' blood types.

The average oxygen saturation $\left(\mathrm{SpO}_{2}\right)$ upon admission was $78 \%$ (range $=20-99 \%$ ), with only $22 \%$ of patients having an $\mathrm{SpO}_{2}>90 \%$. The average temperature $(\mathrm{T})$ of patients upon admission was $37.8^{\circ} \mathrm{C}$ (range $=37-41^{\circ} \mathrm{C}$ ), with $41 \%$ of patients having a $\mathrm{T}>37.5^{\circ} \mathrm{C}$. Most $(81 \%)$ patients presented with shortness of breath and/or cough (53\%); only 2 had anosmia (6\%), and $1(3 \%)$ had diarrhea recorded. A substantial number of patients had multiple comorbidities, particularly diabetes mellitus type 2 (63\%), hypertension (53\%), obesity (38\%), and coronary artery disease (28\%).

Fifty-three percent of admitted patients were transferred to the intensive care unit, and the average length of stay was 17 days (range $=1-28$ days). Fifteen $(47 \%)$ patients required intubation, which continued for a mean of 17 days, $6 \%$ were maintained with bilevel positive airway pressure (BiPAP), and 31\% required a non-rebreather mask. Treatment included a combination of hydroxychloroquine $(20,63 \%)$, antibiotics $(29,91 \%)$, anticoagu- 
Table 1. Patient demographics and clinical information

\begin{tabular}{|c|c|}
\hline Characteristics & $\begin{array}{l}\text { Patients } \\
(n=32)\end{array}$ \\
\hline Age, years & $68(30-100)$ \\
\hline \multicolumn{2}{|l|}{ Gender } \\
\hline Male & $22(69 \%)$ \\
\hline Female & $10(31 \%)$ \\
\hline \multicolumn{2}{|l|}{ Race } \\
\hline White & $12(37 \%)$ \\
\hline Hispanic & $10(31 \%)$ \\
\hline Asian & $5(16 \%)$ \\
\hline Black & $5(16 \%)$ \\
\hline \multicolumn{2}{|l|}{ Site } \\
\hline Home & $23(72 \%)$ \\
\hline Nursing home & $7(22 \%)$ \\
\hline Homeless & $2(6 \%)$ \\
\hline Postmortem interval, median (range), $\mathrm{h}$ & $43(5-382)$ \\
\hline \multicolumn{2}{|l|}{ Smoking history } \\
\hline Never & $17(53 \%)$ \\
\hline Former & $8(25 \%)$ \\
\hline Current & $0(0 \%)$ \\
\hline Unknown & $7(22 \%)$ \\
\hline \multicolumn{2}{|l|}{ Pack-years } \\
\hline Former & $40(10-120)$ \\
\hline \multicolumn{2}{|l|}{ SARS-CoV-2 RT-PCR } \\
\hline Positive & $31(97 \%)$ \\
\hline Not tested & $1(3 \%)$ \\
\hline Fever, ${ }^{\circ} \mathrm{C}$ & $37.8(37-41)$ \\
\hline$<37.5^{\circ} \mathrm{C}$ & $14(41 \%)$ \\
\hline $37.5-38.5^{\circ} \mathrm{C}$ & $5(15 \%)$ \\
\hline$>38.5^{\circ} \mathrm{C}$ & $9(26 \%)$ \\
\hline Unknown & $4(12 \%)$ \\
\hline Admission $\mathrm{SpO}_{2}, \%$ & $78(20-99)$ \\
\hline$>90 \%$ & $7(22 \%)$ \\
\hline $90-75 \%$ & $13(41 \%)$ \\
\hline$<75 \%$ & $7(22 \%)$ \\
\hline $\mathrm{NA}^{\mathrm{a}}$ & $5(15 \%)$ \\
\hline \multicolumn{2}{|l|}{ Cough } \\
\hline Yes & $17(53 \%)$ \\
\hline No & $14(44 \%)$ \\
\hline Unknown & $1(3 \%)$ \\
\hline \multicolumn{2}{|l|}{ Shortness of breath } \\
\hline Yes & $26(81 \%)$ \\
\hline No & $6(19 \%)$ \\
\hline \multicolumn{2}{|l|}{ Anosmia } \\
\hline Yes & $2(6 \%)$ \\
\hline No & $27(84 \%)$ \\
\hline Unknown & $3(10 \%)$ \\
\hline
\end{tabular}

lation $(25,78 \%)$ and/or corticosteroids (2, 6\%). The clinical course was complicated by acute kidney injury (AKI) in $16(50 \%)$ patients, with $6(19 \%)$ requiring renal replacement therapy. Five (16\%) patients developed liver failure. The average overall duration of disease until time of death was 21 days (range: 1-58).

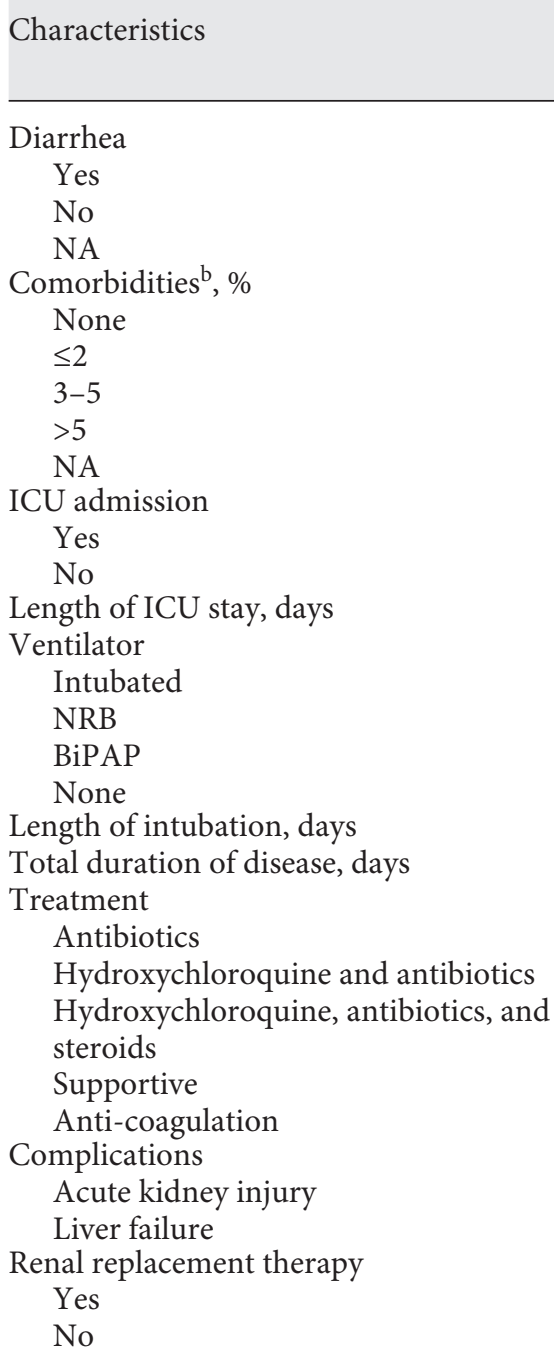

Data are presented as $n$ (\%) and mean (range) unless otherwise stated. SpO2, oxygen saturation; NA, not available; ICU, intensive care unit; NRB, non-rebreather mask; BiPAP, bilevel positive airway pressure; $\mathrm{ACE}$, angiotensin converting enzyme; ARB, angiotensin receptor blocker. ${ }^{\text {a }}$ Intubated on admission or information not available. ${ }^{\mathrm{b}}$ Comorbidities included: hypertension, hyperlipidemia, diabetes, obesity, coronary artery disease, congestive heart failure, chronic obstructive pulmonary disease, asthma, obstructive sleep apnea, end stage renal disease, stroke, dementia, and cancer.

\section{Thrombotic Complications}

Twenty-seven (84\%) of patients had macroscopic and/ or microscopic thrombi at autopsy (Table 3). Twenty-two (69\%) had elevated D-dimers (range: $2-12,200 \mathrm{ng} / \mathrm{mL}$ ). Coagulation factors were also prolonged, with a mean prothrombin time of $24 \mathrm{~s}$ and a mean activated partial 
Table 2. Patient laboratory data

\begin{tabular}{|c|c|}
\hline Parameters & Patients $(n=32)$ \\
\hline \multicolumn{2}{|l|}{ Blood type } \\
\hline $\mathrm{O}+$ & $12(38 \%)$ \\
\hline $\mathrm{A}+$ & $8(25 \%)$ \\
\hline $\mathrm{AB}+$ & $2(6 \%)$ \\
\hline $\mathrm{B}+$ & $2(6 \%)$ \\
\hline A- & $1(3 \%)$ \\
\hline NA & $7(22 \%)$ \\
\hline Hemoglobin, g/dL $(n=31)$ & $11(5.8-15.8)$ \\
\hline $\mathrm{WBC}, \times 10^{3} / \mu \mathrm{L}(n=31)$ & $13(0.5-43.5)$ \\
\hline Lymphocytes, $\%(n=31)$ & $13(1-29)$ \\
\hline Absolute lymphocyte count, $\times 10^{3} / \mu \mathrm{L}(n=30)$ & $2.5(0.1-44.64)$ \\
\hline Neutrophils, $\%(n=31)$ & $77(7-96.1)$ \\
\hline Platelets, $\times 10^{3} / \mu \mathrm{L}(n=31)$ & $188(23-400)$ \\
\hline Troponin-I, ng/mL $(n=31)$ & $3.7(0.01-93.85)$ \\
\hline D-dimer, $\mathrm{ng} / \mathrm{mL}(n=27)$ & $4,848(2-12,200)$ \\
\hline Fibrinogen, $\mathrm{mg} / \mathrm{dL}(n=21)$ & $551(136-1,000)$ \\
\hline Lactate dehydrogenase, $\mathrm{U} / \mathrm{L}(n=26)$ & $1,071(275-4,200)$ \\
\hline Haptoglobin, mg/dL $(n=9)$ & $181(6-340)$ \\
\hline $\mathrm{PT}, \mathrm{s}(n=28)$ & $24(12-80)$ \\
\hline PTT, s $(n=27)$ & $51.6(24.9-150)$ \\
\hline Procalcitonin, $\mathrm{ng} / \mathrm{mL}(n=29)$ & $13.3(0.06-93)$ \\
\hline Erythroid sedimentation rate, $\mathrm{mm} / \mathrm{h}(n=16)$ & $74(10-130)$ \\
\hline Aspartate aminotransferase, $\mathrm{U} / \mathrm{L}(n=31)$ & $567(18-6,000)$ \\
\hline Alanine aminotransferase, $\mathrm{U} / \mathrm{L}(n=31)$ & $387(12-4,885)$ \\
\hline Alkaline phosphatase, $\mathrm{U} / \mathrm{L}(n=31)$ & $142(53-875)$ \\
\hline Total bilirubin, $\mathrm{mg} / \mathrm{dL}(n=31)$ & $1.23(0.2-8.4)$ \\
\hline \multicolumn{2}{|l|}{ Antemortem blood culture } \\
\hline Positive & $5(15 \%)$ \\
\hline Candida albicans & 2 \\
\hline Klebsiella pneumoniae & 1 \\
\hline Escherichia coli & 1 \\
\hline Methicillin-susceptible Staphylococcus aureus & 1 \\
\hline Negative & $23(72 \%)$ \\
\hline NA & $4(13 \%)$ \\
\hline
\end{tabular}

Data are presented as $n(\%)$ or mean (range). WBC, white blood cells; PT, prothrombin time; PTT, partial thromboplastin time.

thromboplastin time of $51.6 \mathrm{~s}$. Thrombi were most frequently in respiratory $(n=25,78 \%)$ and cardiovascular ( $n=8,25 \%$ ) systems (Fig. 1). Macroscopic pulmonary thrombi were detected in $11(34 \%)$ cases.

Small intramyocardial vessels contained microthrombi in $6(19 \%)$ and contained fibrin, platelets, or a mixture of both (Fig. 1). Thrombi were also observed in the prostatic venous plexus, trachea, lymph nodes, and kidney. Several organs showed concurrent parenchymal infarction, including one case of acute myocardial infarction (MI).

\section{Respiratory System}

The clinicopathologic features of the respiratory system are summarized in Table 4. The average combined lung weight was $1,851 \mathrm{~g}$ (range $=1,000-3110 \mathrm{~g}$; reference range $=685-1,050 \mathrm{~g})$. Most patients $(n=24,75 \%)$ had both exudative and proliferative diffuse alveolar damage (DAD). Of those patients, 13 (54\%) were intubated during their hospital course. Three (9\%) patients each showed only acute/exudative DAD or organizing/proliferative $\mathrm{DAD}$. All 3 patients with exudative DAD were never intubated and had a mean duration of disease of 9 days (range $=7-11$ ), while 2 of the 3 patients with proliferative DAD were intubated during their admission and had a mean duration of disease of 35 days (26-42 days). Sixteen (50\%) showed the presence of alveolar neutrophils and 14 (44\%) showed evidence of organizing pneumonia. All cases had some degree of type II pneumocyte hyperplasia with reactive atypia and bronchial squamous metaplasia. 
Table 3. Distribution of thrombi and parenchymal infarcts in organ systems

\begin{tabular}{lcl}
\hline Site & $\begin{array}{l}\text { Thrombi } \\
(n=32)\end{array}$ & $\begin{array}{l}\text { Thrombosis and } \\
\text { coexisting organ } \\
\text { infarction }\end{array}$ \\
& & \\
\hline Heart & $6(19 \%)$ & 1 \\
$\quad$ Intramyocardial small vessel thrombi & $2(6 \%)$ & \\
$\quad$ Valve-associated thrombi & $23(72 \%)$ & 3 \\
Lungs & $11(34 \%)$ & 3 \\
$\quad$ Small vessel thrombi & $9(28 \%)$ & 3 \\
Large vessel thrombi & $4(13 \%)$ & 1 \\
Both & $3(9 \%)$ & 0 \\
Trachea & $3(9 \%)$ & 1 \\
Thyroid & $2(6 \%)$ & 0 \\
Lymph node & $2(6 \%)$ & 1 \\
Bladder & $2(6 \%)$ & 1 \\
Kidney & $1(3 \%)$ & 0 \\
Prostate & $1(3 \%)$ & 0 \\
Esophageal varices & $1(3 \%)$ & 0 \\
Diaphragm & & \\
Ovary & & \\
\hline
\end{tabular}
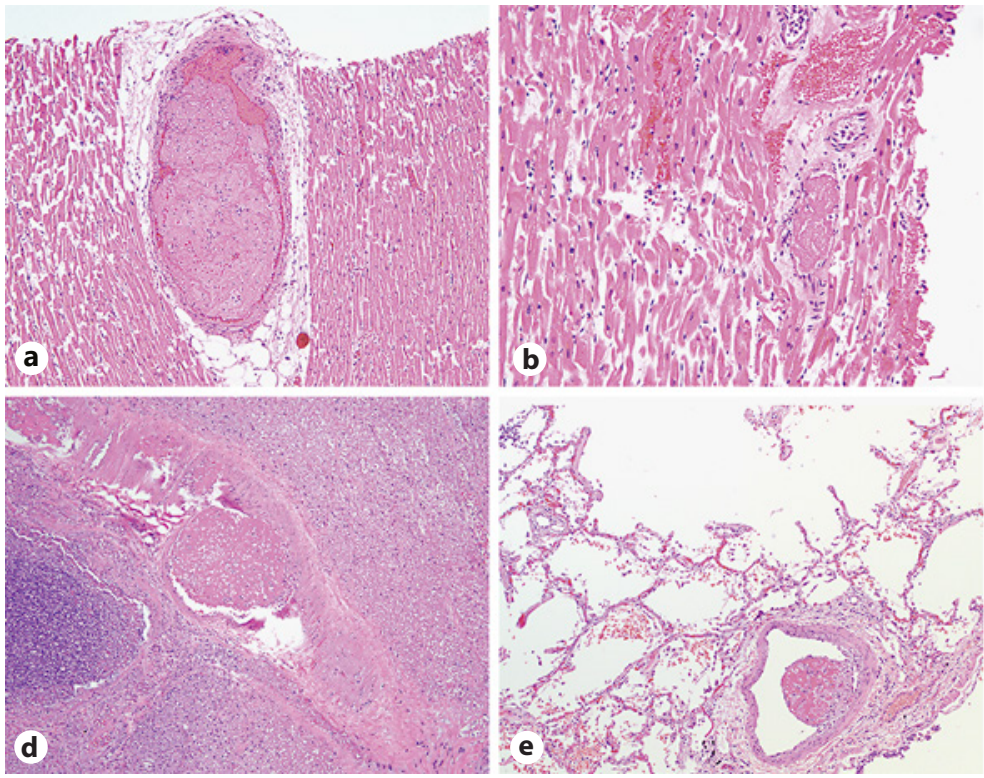

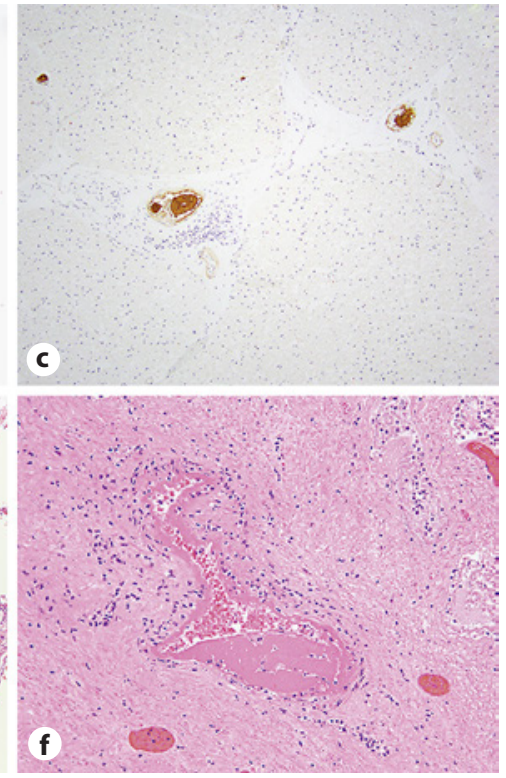

Fig. 1. Multisystem microscopic thromboses were common including in the intracardiac arteries and arterioles $(\mathbf{a}, \mathbf{b} ; \times 20$ and $\times 40)$, highlighted by CD61 immunohistochemistry $(\mathbf{c} ; \times 20)$, in the lung with $(\mathbf{d} ; \times 20)$ or without $(\mathbf{e} ; \times 20)$ associated infarction and in other organs including the prostate $(\mathbf{f} ; \times 40)$.

\section{Cardiovascular System}

Clinicopathologic findings of 30 cases in which examination of the heart was performed are summarized in Table 5. Hypertension was the most common cardiac comorbidity, present in $72 \%$ of cases $(n=23)$. Clinically diagnosed coronary artery disease and chronic heart failure were present in $33 \%$ and $20 \%$ of patients, respectively.
Twelve patients (38\%) had two or more concurrent cardiac comorbidities. The majority of patients had elevated troponin (I) $(n=23,77 \%)$ which averaged $4.89 \mathrm{ng} / \mathrm{mL}$. At autopsy, most patients ( $n=28,93 \%)$ were found to have mild cardiomegaly, average heart weight 494 (g) among women and $515(\mathrm{~g})$ among men. Histologic examination showed myocyte hypertrophy in 24 cases $(80 \%)$ and re- 
Table 4. Pathological characteristics of the lungs

\begin{tabular}{lllll}
\hline Characteristics & DAD & & & \\
\cline { 2 - 5 } & none & exudative & proliferative & both \\
\hline Patients & $2(6 \%)$ & $3(9 \%)$ & $3(9 \%)$ & $24(75 \%)$ \\
$\quad$ Alveolar neutrophils & 1 & 2 & 2 & 11 \\
$\quad$ Organizing pneumonia & 0 & 2 & 3 & 8 \\
$\quad$ Pulmonary edema & 0 & 0 & 0 & 8 \\
Combined lung weights, g & $1,630(1,160-2,100)$ & $1,917(1,830-2,020)$ & $2,050(1,540-2,520)$ & $1,804(1,000-3,110)^{\mathrm{b}}$ \\
Duration of disease, days & $18(1-36)$ & $9(7-11)$ & $35(26-42)$ & $20(1-58)$ \\
Intubated & 0 & 0 & $2(67 \%)$ & $13(52 \%)$ \\
Length of intubation, days & NA & NA & $31(28-33)$ & $15(1-50)$ \\
\hline
\end{tabular}

Data are presented as $n(\%)$ or mean (range). DAD, diffuse alveolar damage; NA, not applicable. ${ }^{\text {a }}$ Reference range for combined lung weights in adults $=685-1,050 \mathrm{~g} .{ }^{\mathrm{b}}$ Combined weight for the right lung and lung biopsy only cases are not applicable.

Table 5. Clinicopathologic features of the cardiovascular system

\begin{tabular}{lcr}
\hline Features & Patients $(n=30)$ & Average \\
\hline Clinical findings & & \\
$\quad$ Coronary artery disease & $10(33 \%)$ & \\
Chronic heart failure & $6(20 \%)$ & \\
Hypertension & $21(70 \%)$ & $3.7(\mathrm{ng} / \mathrm{mL})$ \\
Troponin (I) & & $0.027(\mathrm{ng} / \mathrm{mL})$ \\
$\quad$ Normal & $6(20 \%)$ & $4.89(\mathrm{ng} / \mathrm{mL})$ \\
$\quad$ Elevated & $23(77 \%)$ & $480(\mathrm{~g})$ \\
Pathologic findings & & $350(\mathrm{~g})$ \\
Heart weight & & $490(\mathrm{~g})$ \\
$\quad$ Normal weight & $2(6 \%)$ & \\
Cardiomegaly & $28(93 \%)$ & \\
Histologic features & & \\
Atherosclerosis $(>50 \%$ stenosis $)$ & $17(57 \%)$ & \\
Myocyte hypertrophy & $24(80 \%)$ & \\
Myocyte ischemia & $5(17 \%)$ & \\
Interstitial fibrosis & $20(67 \%)$ & \\
\hline
\end{tabular}

${ }^{a}$ Normal troponin-I: $\leq 0.04 \mathrm{ng} / \mathrm{mL} .{ }^{\mathrm{b}}$ Normal heart weight: male $270-360 \mathrm{~g}$, female $200-280 \mathrm{~g}$. mote myocardial injury in 20 patients $(67 \%)$ as patchy interstitial fibrosis. Survey of the coronary tree showed at least moderate atherosclerosis $(>50 \%)$ in 17 patients $(57 \%)$. Acute myocardial ischemia was observed in a minority of patients $(n=5,17 \%)$. Of these patients, 1 had acute MI due to thrombosis or hemorrhage into an atherosclerotic plaque of a major coronary artery along with concurrent COVID-19. One patient had persistent lymphocytic myocarditis, diagnosed 38 days prior to the onset of respiratory symptoms and prior to the diagnosis of COVID-19. No other myocarditis or cardiac amyloid was seen in our cohort.

Autopsy Findings in COVID-19

\section{Hepatobiliary System}

Histopathologic abnormalities were observed in the livers of $17(61 \%)$ patients. Steatosis was present in 9 (32\%) cases and represented the most common finding and could be explained by concomitant obesity, diabetes mellitus, and/or hyperlipidemia. Nonspecific portalbased mild lymphocytic inflammation was present in 6 (21\%) cases. Three cases showed evidence of chronic liver disease with bridging fibrosis and/or cirrhosis of unclear etiology. One patient had a poorly preserved intraductal trematode consistent with Fasciola hepatica. Large peculiar basophilic structures were found in the 
Fig. 2. Liver showing steatosis and large, atypical basophilic sinusoidal structures as seen in 2 separate cases. a H\&E, $\times 20$. b PAS-D, $\times 20$. c H\&E, $\times 40$. d PAS-D $\times 40$.
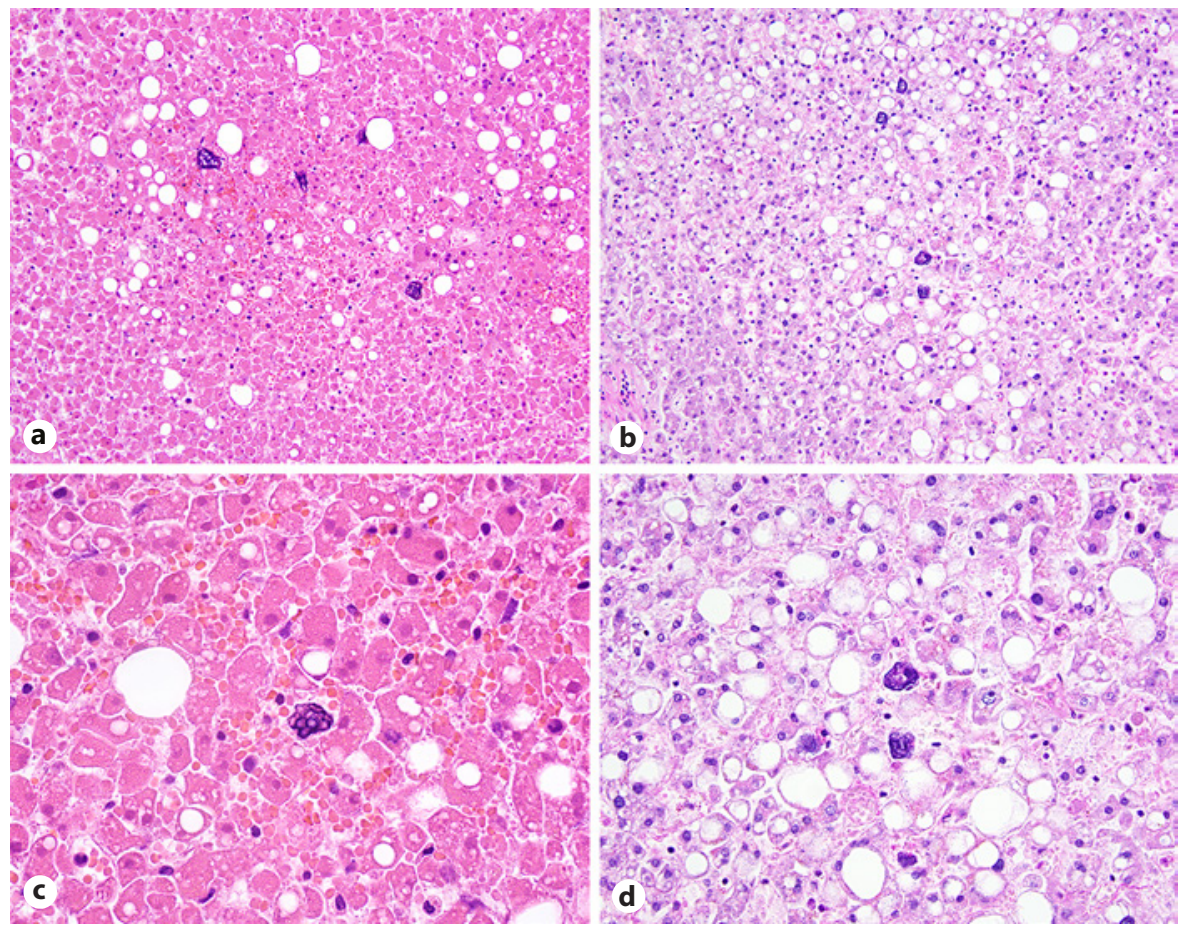

sinusoids of 10 (36\%) cases (Fig. 2). These structures were surrounded by scant or no cytoplasm and were thought to represent nuclear remnants of altered cells. Attempts to define their nature by immunohistochemistry using markers for megakaryocytes (CD61), histiocytes (CD163), and endothelial cells (ERG) were unsuccessful.

\section{Hematopoietic System}

Sections of the spleen and/or lymph nodes were examined from all 32 cases. Due to safety concerns, bone marrow was not obtained except in 2 cases. Lymph nodes submitted included hilar, mediastinal, paraesophageal, and paraaortic. Microscopic examination showed variable degrees of autolysis in the spleen and lymph node tissues. Thus, only a select group of lymph nodes (18 patients) and spleens (14 patients) from autopsies performed 1-7 days after death were reviewed. Even with this restriction, the spleens showed significant autolysis, precluding accurate histologic evaluation. The lymph nodes demonstrated relatively preserved architecture, except for one patient with splenic marginal zone lymphoma (SMZL), with morphologically intact lymphoid follicles containing centrally located germinal centers ( 15 cases), paracortical areas, and patent sinuses (Fig. 3a). This was confirmed by immu- nostaining with CD20 highlighting the intact follicles with central CD10-positive germinal center cells outlined by CD3-positive T cells (Fig. 3b-d). The subcapsular and intraparenchymal sinuses were frequently expanded and often contained a variable number of larger transformed cells with prominent nucleoli and amphophilic cytoplasm (Fig. 3e-f), which were variably CD20 positive by immunostaining (Fig. $3 \mathrm{e}$ inset). These transformed cells, some of which were immunoblast-like in appearance, were also seen scattered, next to vascular channels or sinuses and in loose groups in the paracortical region. In at least 2 cases, the loose groups of these larger cells were associated with apoptotic debris. These larger cells were present in all cases including the case of SMZL. Except for the scattered larger transformed cells, the cells in the paracortical areas were largely small lymphocytes or plasma cells. In some cases, the plasma cells were the prominent cell population. While most cases showed predominately CD3-positive T cells in the paracortical areas by immunostaining, a few cases had more CD20-positive B cells than usual. In addition, many lymph nodes showed prominent vascular congestion. The 3 cases where germinal centers were not identified were from patients who had SMZL (1), were under treatment for acute myeloid leukemia (1), or had significant fibrosis associated with anthracotic pigment (1). How- 
Fig. 3. Lymph nodes with preserved architecture (a; H\&E, $\times 20)$, including intact follicles highlighted by CD3 (b; IHC, $\times 20$ ), CD20 (c; IHC, $\times 20)$, and CD10 (d; IHC, $\times 20)$. The subcapsular and intraparenchymal sinuses contain large transformed cells with prominent nucleoli and amphophilic cytoplasm (e, f; H\&E with oil immersion, $\times 100$ ), which stain for CD20 (e, inset, IHC, $\times 60)$.
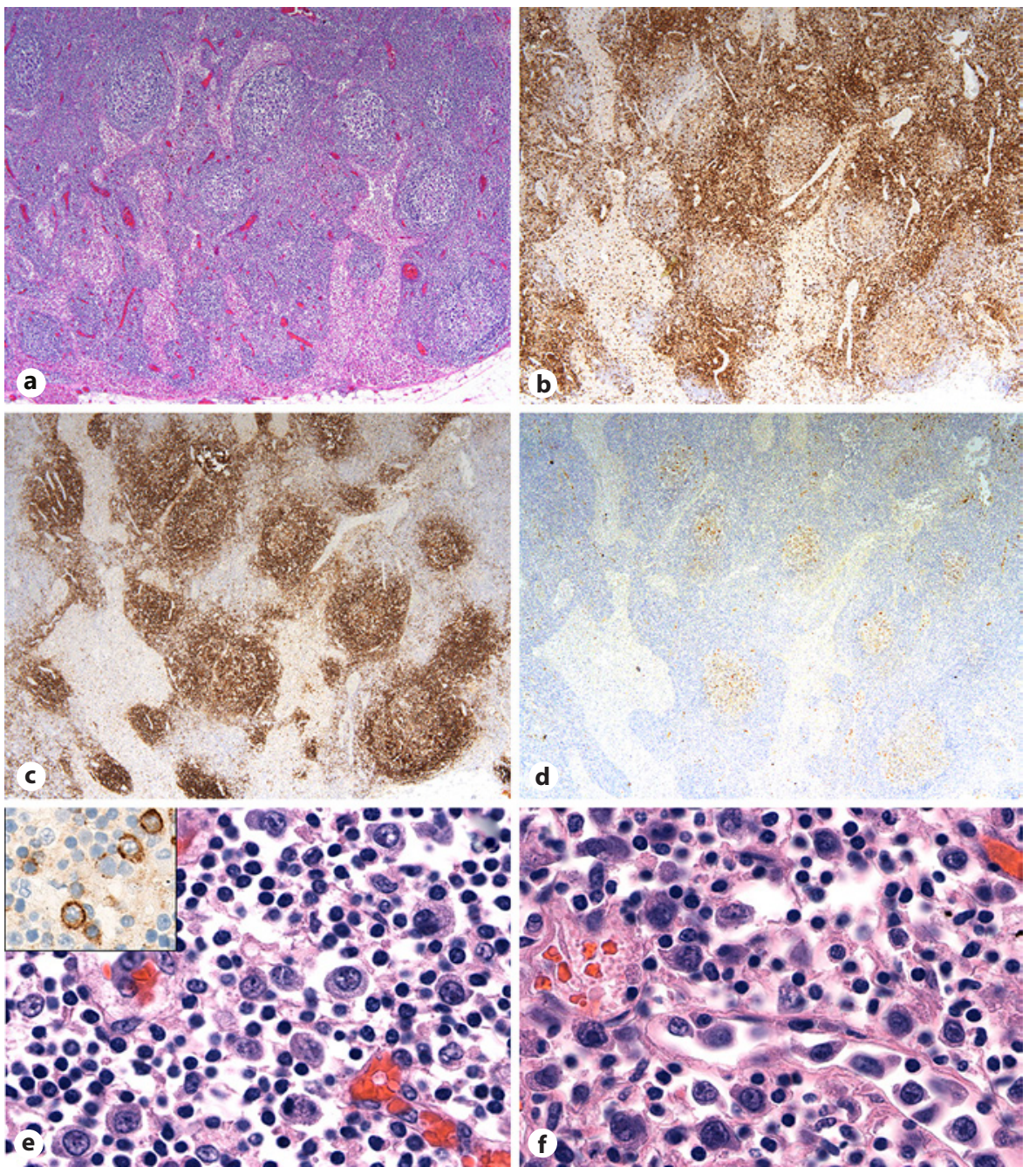

ever, the latter 2 cases showed otherwise normal architectural features including sinuses.

\section{Kidney}

Clinical parameters for comorbidities and renal function tests on all 32 patients are summarized in Table 6 . Diabetes and hypertension were frequently present, and patients had subsequent associated chronic kidney disease. Two patients had ESRD at the time of autopsy, while 16 had AKI corresponding to the onset of viral infection. Five (17\%) required new renal replacement therapy. Presenting creatinine ranged from 0.66 to $9.6 \mathrm{mg} / \mathrm{dL}$ (mean $1.7 \mathrm{mg}$ / dL). Proteinuria was present in 9 patients with $2+$ to $3+$ intensity (of 18 with urinalysis performed), but no quantification was undertaken in any patients in this cohort.

Histologic examination was available for 28 autopsies. The pathology correlated with their underlying comor- bidities, including diabetic nephropathy in 14 patients (50\%), extensive tubulointerstitial scarring (>25\%) in $43 \%$ of cases, with moderate to severe vascular sclerosis in $79 \%$ of cases (Fig. 4). Tubular autolysis precluded assessment of acute tubular injury in the majority of cases, which was likely the main etiology of AKI on chronic kidney disease. The peritubular capillaries were dilated in nearly all cases with inflammatory margination frequently identified. Rare other pathologic diagnoses were also seen (Table 6; Fig. 4). Two cases showed thrombotic microangiopathy of the glomeruli with acute thrombi focally present within the glomerular hilar vessels and/or peripheral capillary loops leading to endothelial swelling and luminal closure. Evidence of complement-mediated endothelial injury was identified by C 5 b- 9 staining in up to $67 \%$ of cases, including the 2 with frank thrombi (Table 6; Fig. 4e). 
Table 6. Clinicopathologic features of the kidneys

\begin{tabular}{|c|c|c|}
\hline Feature & Patients $(n=32)$ & Notes \\
\hline \multicolumn{3}{|l|}{ Clinical findings } \\
\hline Diabetes/pre-diabetes & $20(63 \%)$ & \\
\hline Hypertension & $23(72 \%)$ & \\
\hline Obesity & $10(31 \%)$ & \\
\hline Acute kidney injury & $16(53 \%)$ & $n=30^{\mathrm{a}}$ \\
\hline Requiring renal replacement therapy & $5(17 \%)$ & $n=30^{\mathrm{a}}$ \\
\hline Creatinine, $\mathrm{mg} / \mathrm{dL}$ & Range: $0.66-9.61(n=29)$ & Mean 1.7 \\
\hline Proteinuria & $9(50 \%)(n=18)$ & None quantitated \\
\hline \multicolumn{3}{|l|}{ Pathologic findings $(n=28)^{\mathrm{b}}$} \\
\hline Diabetic nephropathy & $14(50 \%)$ & \\
\hline Diffuse mesangial glomerulosclerosis & $11(39 \%)$ & \\
\hline Nodular mesangial glomerulosclerosis & $3(11 \%)$ & \\
\hline \multicolumn{3}{|l|}{ Other diagnoses } \\
\hline Obesity related glomerulopathy & 2 & \\
\hline Papillary Necrosis & 2 & \\
\hline Thrombotic microangiopathy & 2 & \\
\hline Atheroembolic disease & 1 & \\
\hline Bilateral infarction & 1 & \\
\hline Global glomerulosclerosis & $5-95 \%$ & Mean $22.7 \%^{\mathrm{b}}$ \\
\hline \multicolumn{3}{|l|}{ Interstitial fibrosis and tubular atrophy } \\
\hline$<25 \%$ & $16(57 \%)$ & \\
\hline $26-50 \%$ & $7(25 \%)$ & \\
\hline$>50 \%$ & $5(18 \%)$ & \\
\hline \multicolumn{3}{|l|}{ Vascular sclerosis } \\
\hline Mild & $6(21 \%)$ & \\
\hline Moderate & $10(36 \%)$ & \\
\hline Severe & $12(43 \%)$ & \\
\hline \multicolumn{3}{|l|}{ C5b-9 immunohistochemical staining } \\
\hline Cases in arterioles & $67 \%$ & \\
\hline Cases in glomeruli & $21 \%$ & \\
\hline
\end{tabular}

\section{Discussion}

In this study, we described the unique and multisystem clinical and pathologic findings in 32 autopsies of patients who died from the novel coronavirus, SARS-CoV-2. Clinically, our patient cohort was older with multiple underlying comorbidities, similar to those described in other publications $[1,4]$. The majority of patients were male, on average in their late $60 \mathrm{~s}$, and had an average of $4 \mathrm{co}-$ morbidities, most commonly hypertension, coronary artery disease, obesity, and diabetes. More than half of the patients were Caucasian or Hispanic, but in distinction to studies from the Chinese and European literature, ours was a diverse patient population with deaths seen across the ethnic spectrum [18-20]. The most common presenting symptoms were shortness of breath, cough, and a low- grade fever. On histologic examination, we observed findings secondary to the patients' preexisting conditions in the heart, lungs, liver, and kidneys, as well as changes secondary to SARS-CoV-2 infection such as various stages of DAD and multiple thromboemboli in large and small vessels in multiple organs.

As previously reported, lung injury was the main cause of death in our patients $[4,8]$. The virus is believed to infect the epithelial lining cells of the respiratory tract using the ACE2 enzyme as a viral receptor leading to DAD, ede$\mathrm{ma}$, and a marked increase in lung weights at autopsy. Notably, the lung pathology was heterogeneous, corresponding to the radiographic findings of patchy ground glass opacifications, and on histology the pulmonary parenchyma demonstrated a range of findings from patchy exudative hyaline membrane disease to organizing pneu- 

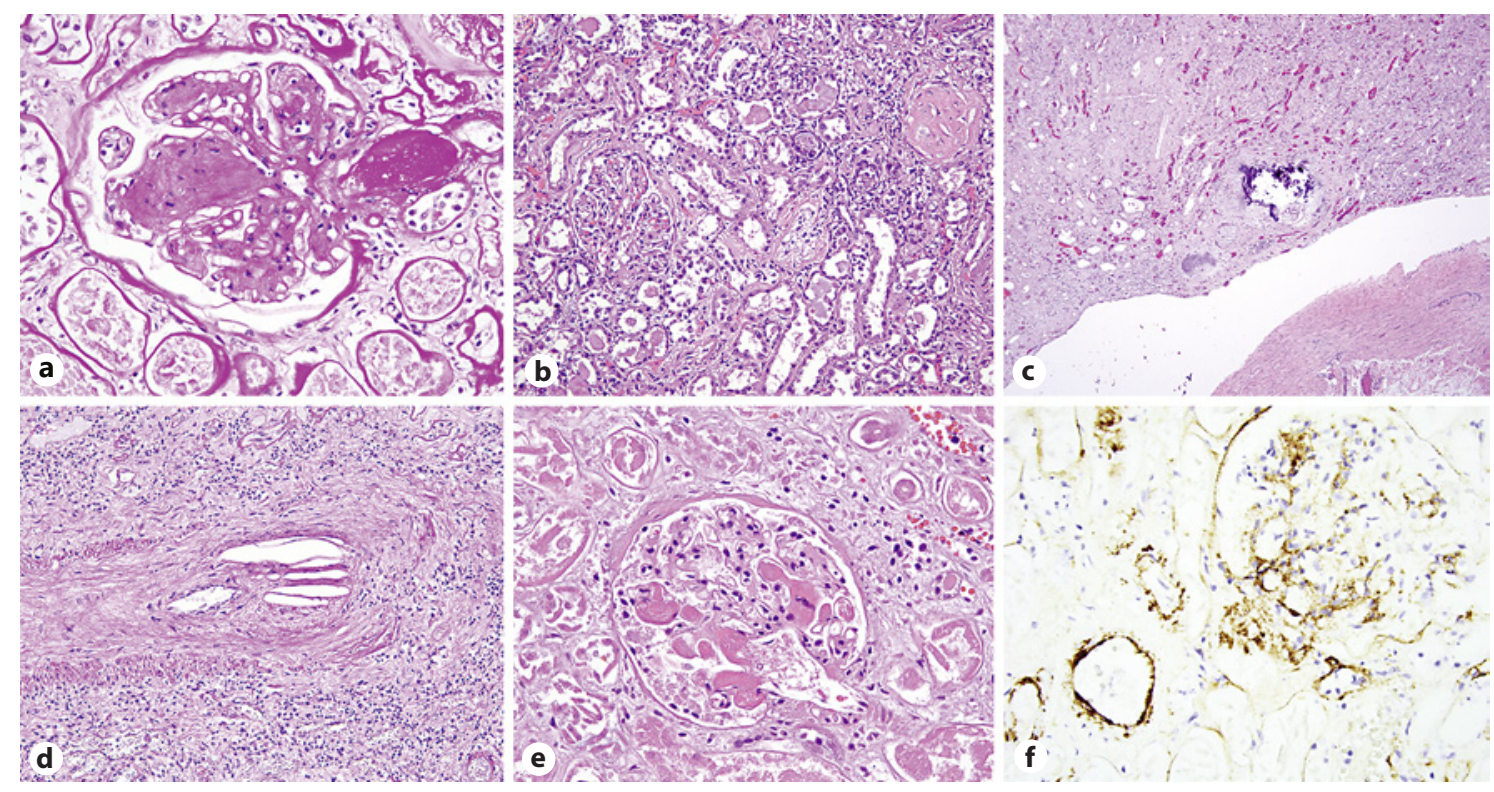

Fig. 4. Kidney showing prominent changes of diabetic nephropathy including mesangial diabetic glomerulosclerosis and extensive arteriolar hyalinosis (a; PAS, $\times 40)$, acute tubular necrosis $(\mathbf{b} ; \mathrm{H} \& \mathrm{E}, \times 20)$, papillary necrosis (c; $H \& E, \times 4)$, atheroembolic disease (d; PAS, $\times 20)$, glomerular thrombotic microangiopathy (e; H\&E, $\times 40)$, and glomerular and arteriolar endothelial staining for C5b-9 (f; IHC, ×40).

monia, while some areas were histologically normal. These features are most likely indicative of the spread of virus in the lung, but future studies are needed to investigate this in greater detail.

Multiple authors have reported clinical evidence of cardiac injury seen in the form of elevated troponins, and pathologically concurrent MI and myocarditis $[1,4,21-$ 24]. Similar to other studies, the majority of our patients had elevated troponin (I) [8]. The most significant histologic finding in our cohort was the presence of intramyocardial thrombi, identified in 19\% of patients. Currently, it is known that endothelial injury and thrombosis are seen in patients with SARS-CoV-2 infection as a part of microangiopathy [25]. Thrombi are most frequently seen in the lungs $[19,25]$. However, few reports address microthrombi in the myocardium, which we found in these patients when evaluating random heart sections. We believe that SARS-CoV-2-infected patients have a propensity to develop microthrombi in the myocardial vessels which correspond to microthrombi also seen in other organs. Microthrombi are not typically seen in the microcirculation of the heart in conditions other than thrombotic thrombocytopenic purpura and hemolytic uremic syndrome $[26,27]$. While frank myocardial ischemia was not frequently present, except in 1 case with well-documented MI, the elevated troponins and clinical myocar- dial dysfunction may be due to small-vessel thromboses in addition to general hypoxia.

SARS-CoV-2 has also been reported to cause myocarditis, mostly reported based on imaging and electrocardiogram changes $[22,23,28]$. As more studies emerge, the link of COVID-19 and viral-associated myocarditis does not appear to have a major role, if any, in the cardiac injury in these patients. In our series, one patient had lymphocytic myocarditis at autopsy. However, the patient had underlying congenital heart disease requiring multiple surgeries, and the myocarditis was temporally distant, arising earlier than viral symptoms. Therefore, we believe it was unrelated to the viral infection. No other patient had any inflammatory infiltrates in the heart. No viral inclusion was observed in any cases.

Liver injury, in the form of moderately elevated aminotransferases, has been reported in up to $53 \%$ of patients [29]. Rare patients have transaminases rise above a thousand [30]. In contrast to the cardiovascular pathology, few patients had preexisting chronic disease, with the exception of steatosis, similar to other studies [18, 29-31]. Close to a half of our cohort exhibited moderately elevated aspartate and alanine aminotransferase enzymes, and a minority of patients $(n=5)$ developed acute liver failure of unclear etiology. The presence of ACE- 2 which is integral for viral entry into the cells is present more on chol- 
angiocytes compared to hepatocytes; however, no significant elevation in bilirubin or histologic evidence of ductular injury was seen, similar to the study by Fan et al. [32]. Nuclear material of SARS-CoV has been detected in the liver by RT-PCR [33, 34]; however, no specific histologic correlate of direct hepatocyte injury by SARS-CoV has been reported with the exception of nonspecific findings of acidophil bodies, ballooning hepatocytes, and atypical mitoses. Drug-mediated liver damage may confound the interpretation of hepatocyte injury in these patients particularly when treated with lopinovir and ritonavir for COVID-19 [32]. However, our patients have been treated predominately with hydroxychloroquine which is not known to cause direct liver injury [35].

A number of mechanisms have been proposed to induce clinically observed liver damage in COVID patients such as locoregional viral replication, cytokine storm, hypoxia, hypovolemia, and acute on chronic injury of preexisting conditions $[33,36]$. We have observed peculiar previously unreported basophilic structures of unknown origin, in $36 \%$ of patients. These structures are singly scattered and located predominately in sinusoids. While immunohistochemical staining failed to prove their identity as macrophage, megakaryocytic, or endothelial derived structures, there is a possibility that IHC staining was compromised on this autolyzed autopsy material. As one of these patients had blue-green crystals in circulating monocytes and neutrophils premortem, which have been ascribed to liver injury in the literature, it is possible that these structures are related [37]. By further identification and study of these structures, hopefully full characterization will be possible.

The renal manifestations of AKI in these patients are mostly due to acute tubular injury in addition to chronic diseases from the patients' underlying conditions, particularly diabetes and hypertension, confirming that seen in prior studies $[3,4]$. Acute tubular injury may be related to tubular ischemia alone such as hemodynamic changes or could be further exacerbated by direct viral infection, cytokine mediated injury, or drug-related tubular toxicity. Considerable renovascular disease is present with moderate-to-severe sclerosis in $80 \%$ of cases, atheroemboli, papillary necrosis, and 2 cases of glomerular fibrin thrombi also detected. The latter corresponding to patients with more widespread multiorgan thromboses, but overall the majority (67\%) had evidence of complement-mediated endothelial injury, by C5b-9 staining, potentially indicating a role of viral-associated endothelial pathology.

Although the primary target of coronaviruses is the respiratory system, coronaviruses are known to cause dis- seminated infection [33]. One of unusual sites is the hematopoietic system. Clinically patients have lymphopenia and mild thrombocytopenia, as seen in this study. Previously reported lymphocyte depletion in the lymph nodes and absent germinal centers have not been observed in this cohort [8]. We have seen preservation of lymph node architecture with addition of sinus dilatation and congestion, similar to that reported by Menter et al. [18]. It is unclear if viral proteins are present within the lymph nodes and therefore whether morphologic changes in the lymph nodes are a direct consequence of viral replication or a nonspecific change to a viral infection.

Overall, the autopsies show 2 patterns of injury, chronic and acute. The patients had significant underlying comorbidities, and the more chronic pathologic changes reflect that, including the chronic kidney disease namely diabetic nephropathy and vascular sclerosis, the cardiac hypertrophy, patchy cardiac fibrosis, and coronary artery disease, as well as the hepatic steatosis and nonspecific fibrosing changes. On top of those, there are acute changes either directly due to viral infection or associated with the recent infection which include the pulmonary DAD, widespread microscopic thrombi and associated organ infarcts, reactive lymph node changes with immunoblastic-type cells, atypical hepatic sinusoidal concretions/ cells, renal TMA, and acute tubular injury in the kidneys.

The autopsies all came from a 2-month period of time when the treatment the patients received was largely antibiotics plus or minus hydroxychloroquine in $78 \%$ of these cases. As the microthrombi became a more regarded complication, anticoagulation was also utilized, also in $78 \%(n=25)$ of the cases. However, of those 25, 19 still were found to have thrombi in the lungs at autopsy and of the 6 without pulmonary thrombi, 2 had other organ involvement bringing the total to 21 of 25 patients. In comparison, 6 of the 7 patients who were not anti-coagulated also showed thrombi. Steroids were not frequently utilized and only given to 2 patients, for 3 days each, 17 and 24 days prior to their death. Larger studies are needed to further investigate the impact of anticoagulation and immunosuppression in this disease.

In conclusion, this autopsy series of 32 ethnically diverse patients with SARS-CoV-2 infection from a single NYC autopsy service shows a multisystemic pathology which leads to death typically in those with comorbidities. While the lung findings are most significant for the majority of those infected, other organ systems are frequently involved including with widespread microscopic thromboses in numerous organs, as well as liver, kidney, and lymph node pathology. Autopsy findings in
66

Pathobiology 2021;88:56-68 DOI: $10.1159 / 000511325$
Elsoukkary et al. 
these most severely affected patients can serve as a valuable source of information in studying this new disease process.

\section{Acknowledgment}

The authors wish to acknowledge Nector Garcia, Alisa Ramineni, Dr. Amelia Baxter-Stoltzfus, Dr. Mona Farahi, Dr. William Towne, Dr. Kartik Viswanathan, Dr. Elizabeth Crowe, and Dr. Paul Barone for their assistance in performing the autopsies.

\section{Statement of Ethics}

The study was exempt from institutional review board approval as it did not meet criteria for living human research; however, informed consent was obtained from the next of kin for all patients.

\section{Conflicts of Interest Statement}

The authors have no conflicts of interest to declare.

\section{Funding Sources}

None.

\section{Author Contributions}

S.S.E., M.M., A.C.B., S.P.S. designing study, acquiring data, analyzing data, writing manuscript. A.D., D.R.B., L.X.M. acquiring data. A.C., R.K.Y., J.J., S.V.S. analyzing data, writing manuscript. All authors participated in revising and approving the manuscript.

\section{References}

1 Ge H, Wang X, Yuan X, Xiao G, Wang C, Deng $\mathrm{T}$, et al. The epidemiology and clinical information about COVID-19. Eur J Clin Microbiol Infect Dis. 2020 Jun;39(6):1011-1019.

2 Hassan SA, Sheikh FN, Jamal S, Ezeh JK, Akhtar A. Coronavirus (COVID-19): A Review of Clinical Features, Diagnosis, and Treatment. Cureus. 2020 Mar;12(3):e7355.

3 Chen G, Wu D, Guo W, Cao Y, Huang D, Wang $\mathrm{H}$, et al. Clinical and immunological features of severe and moderate coronavirus disease 2019. J Clin Invest. 2020 May; 130(5): 2620-9.

4 Chen T, Wu D, Chen H, Yan W, Yang D, Chen G, et al. Clinical characteristics of 113 deceased patients with coronavirus disease 2019: retrospective study. BMJ. 2020 Mar; 368:m1091.

5 WHO. Coronavirus disease (COVID-19) Situation Report - 163. Geneva: WHO; 2020.

6 Hamming I, Timens W, Bulthuis ML, Lely AT, Navis G, van Goor H. Tissue distribution of ACE2 protein, the functional receptor for SARS coronavirus. A first step in understanding SARS pathogenesis. J Pathol. 2004 Jun; 203(2):631-7.

7 Barton LM, Duval EJ, Stroberg E, Ghosh S, Mukhopadhyay S. COVID-19 Autopsies, Oklahoma, USA. Am J Clin Pathol. 2020 May; 153(6):725-33.

8 Lax SF, Skok K, Zechner P, Kessler HH, Kaufmann N, Koelblinger C, et al. Pulmonary Arterial Thrombosis in COVID-19 With Fatal Outcome : Results From a Prospective, Single-Center, Clinicopathologic Case Series. Ann Intern Med. 2020 Sep;173(5):350-61.

9 Tian S, Hu W, Niu L, Liu H, Xu H, Xiao SY. Pulmonary Pathology of Early-Phase 2019 Novel Coronavirus (COVID-19) Pneumonia in Two Patients With Lung Cancer. J Thorac Oncol. 2020 May;15(5):700-04.
10 Edler C, Schröder AS, Aepfelbacher M, Fitzek A, Heinemann A, Heinrich F, et al. Dying with SARS-CoV-2 infection-an autopsy study of the first consecutive 80 cases in Hamburg, Germany. Int J Legal Med. 2020 Jul;134(4): 1275-84.

11 Dell'Aquila M, Cattani P, Fantoni M, Marchetti S, Aquila I, Stigliano E, et al. Postmortem swabs in the Sars-CoV-2 Pandemic: report on 12 complete clinical autopsy cases. Arch Pathol Lab Med. 2020 Jun. https://doi. org/10.5858/arpa.2020-0362-SA.

12 Farkash EA, Wilson AM, Jentzen JM. Ultrastructural Evidence for Direct Renal Infection with SARS-CoV-2. J Am Soc Nephrol. 2020 Aug;31(8):1683-7.

13 Hui KP, Peiris M, Nicholls JM, Chan MC. SARS-CoV-2 infection in conjunctival tissue - Authors' reply. Lancet Respir Med. 2020 Jul; 8(7):e58.

14 Schaefer IM, Padera RF, Solomon IH, Kanjilal S, Hammer MM, Hornick JL, et al. In situ detection of SARS-CoV-2 in lungs and airways of patients with COVID-19. Mod Pathol. 2020 Jun 19;1-11.

15 Schaller T, Hirschbühl K, Burkhardt K, Braun G, Trepel M, Märkl B, et al. Postmortem Examination of Patients With COVID-19. JAMA. 2020 May;323(24):2518.

16 Sekulic M, Harper H, Nezami BG, Shen DL, Sekulic SP, Koeth AT, et al. Molecular Detection of SARS-CoV-2 Infection in FFPE Samples and Histopathologic Findings in Fatal SARS-CoV-2 Cases. Am J Clin Pathol. 2020 Jul;154(2):190-200.

17 Tombolini A, Scendoni R. SARS-CoV-2-related deaths in routine forensic autopsy practice: histopathological patterns. Int J Legal Med. 2020 Jun. https://doi.org/10.1007/ s00414-020-02354-5.
18 Menter T, Haslbauer JD, Nienhold R, Savic S, Hopfer H, Deigendesch N, et al. Postmortem examination of COVID-19 patients reveals diffuse alveolar damage with severe capillary congestion and variegated findings in lungs and other organs suggesting vascular dysfunction. Histopathology. 2020 May;77(2): 198-209.

19 Wichmann D, Sperhake JP, Lütgehetmann M, Steurer S, Edler C, Heinemann A, et al. Autopsy Findings and Venous Thromboembolism in Patients With COVID-19: A Prospective Cohort Study. Ann Intern Med. 2020 Aug;173(4):268-77.

20 Fogarty H, Townsend L, Ni Cheallaigh C, Bergin C, Martin-Loeches I, Browne P, et al. COVID19 coagulopathy in Caucasian patients. Br J Haematol. 2020 Jun; 189(6):1044-9.

21 Bikdeli B, Madhavan MV, Jimenez D, Chuich T, Dreyfus I, Driggin E, et al.; Global COVID-19 Thrombosis Collaborative Group, Endorsed by the ISTH, NATF, ESVM, and the IUA, Supported by the ESC Working Group on Pulmonary Circulation and Right Ventricular Function. COVID-19 and Thrombotic or Thromboembolic Disease: Implications for Prevention, Antithrombotic Therapy, and Follow-Up: JACC State-of-the-Art Review. J Am Coll Cardiol. 2020 Jun;75(23): 2950-73.

22 Craver R, Huber S, Sandomirsky M, McKenna D, Schieffelin J, Finger L. Fatal Eosinophilic Myocarditis in a Healthy 17-Year-Old Male with Severe Acute Respiratory Syndrome Coronavirus 2 (SARS-CoV-2c). Fetal Pediatr Pathol. 2020 Jun;39(3):263-8.

23 Doyen D, Moceri P, Ducreux D, Dellamonica J. Myocarditis in a patient with COVID-19: a cause of raised troponin and ECG changes. Lancet. 2020 May;395(10235):1516. 
24 Ruan Q, Yang K, Wang W, Jiang L, Song J. Clinical predictors of mortality due to COVID-19 based on an analysis of data of 150 patients from Wuhan, China. Intensive Care Med. 2020 May;46(5):846-8.

25 Ackermann M, Verleden SE, Kuehnel M, Haverich A, Welte T, Laenger F, et al. Pulmonary Vascular Endothelialitis, Thrombosis, and Angiogenesis in Covid-19. N Engl J Med. 2020 Jul;383(2):120-8.

26 Kremer Hovinga JA, Coppo P, Lämmle B, Moake JL, Miyata T, Vanhoorelbeke K. Thrombotic thrombocytopenic purpura. Nat Rev Dis Primers. 2017 Apr;3(1):17020.

27 Wiernek SL, Jiang B, Gustafson GM, Dai X. Cardiac implications of thrombotic thrombocytopenic purpura. World J Cardiol. 2018 Dec;10(12):254-66.

$28 \mathrm{Hu} \mathrm{H}, \mathrm{Ma} \mathrm{F}$, Wei X, Fang Y. Coronavirus fulminant myocarditis saved with glucocorti- coid and human immunoglobulin. Eur Heart J. 2020 Mar;ehaa190.

29 Zhang C, Shi L, Wang FS. Liver injury in COVID-19: management and challenges. Lancet Gastroenterol Hepatol. 2020 May;5(5):42830.

30 Xu L, Liu J, Lu M, Yang D, Zheng X. Liver injury during highly pathogenic human coronavirus infections. Liver Int. 2020 May;40(5): 998-1004.

31 Mantovani A, Beatrice G, Dalbeni A. Coronavirus disease 2019 and prevalence of chronic liver disease: A meta-analysis. Liver Int. 2020 Jun;40(6):1316-20.

32 Fan Z, Chen L, Li J, Cheng X, Yang J, Tian C, et al. Clinical Features of COVID-19-Related Liver Functional Abnormality. Clin Gastroenterol Hepatol. 2020 Jun;18(7):1561-66.

33 Farcas GA, Poutanen SM, Mazzulli T, Willey BM, Butany J, Asa SL, et al. Fatal severe acute respiratory syndrome is associated with multiorgan involvement by coronavirus. J Infect Dis. 2005 Jan;191(2):193-7.

34 Gu J, Han B, Wang J. COVID-19: Gastrointestinal Manifestations and Potential FecalOral Transmission. Gastroenterology. 2020 May;158(6):1518-9.

35 Hydroxychloroquine. LiverTox: Clinical and Research Information on Drug-Induced Liver Injury. Bethesda: National Institute of Diabetes and Digestive and Kidney Diseases; 2012.

36 Li J, Fan JG. Characteristics and Mechanism of Liver Injury in 2019 Coronavirus Disease. J Clin Transl Hepatol. 2020 Mar;8(1):13-7.

37 Cantu MD, Towne WS, Emmons FN, Mostyka M, Borczuk A, Salvatore SP, et al. Clinical significance of blue-green neutrophil and monocyte cytoplasmic inclusions in SARSCoV-2 positive critically ill patients. Br J Haematol. 2020 Jul;190(2):e89-92. 